\title{
Common Design Problems and Optimization Measures for Flat Slab Floor Structures
}

\author{
Jingjing Liu ${ }^{1, *}$, Haoyu Zhang $^{2}$ \\ ${ }^{1}$ School of Civil Engineering and Architecture, Wuhan Polytechnic University, China \\ ${ }^{2}$ Graduate School of Engineering, Kobe University, Japan
}

\begin{abstract}
Compared with the traditional beam-slab structure, the flat slab floor structure has the advantages of simple load transmission path, beautiful appearance and outstanding economic benefits. It is widely used in the roof design of residential underground garages. In recent years, there have been many roof collapse accidents of underground garage in China. This makes the safety of the beamless floor become a hot topic. As a common structural form, the flat slab floor structure has the advantages of cost saving and convenient construction, but the potential risk factors for continuous collapse are more complicated than the traditional structure. Therefore, the study of the mechanical behaviour of the flat slab floor structure is very important. The article points out some common problems in the design of flat slab floor, and proposes many optimization and improvement measures, such as considering unbalanced bending moments and construction conditions, improving design methods, adding structural measures, etc.
\end{abstract}

\section{Background}

In August 2019, a construction quality accident occurred in a construction project in Nanchang County, Nanchang City, China. During the construction of the earthwork backfill on the garage roof by the excavator, the construction crew found that the roof of the underground garage had cracked and collapsed. The scene of the accident is shown in Figure 1.The area of the collapsed area is about $500 \mathrm{~m}^{2}$. The underground garage is located below the open space between the 5\# and 10\# buildings of the residential community. According to the original design, the construction workers will cover the soil on the roof of the basement and plant vegetation. The basement roof structure system is a flat slab floor.

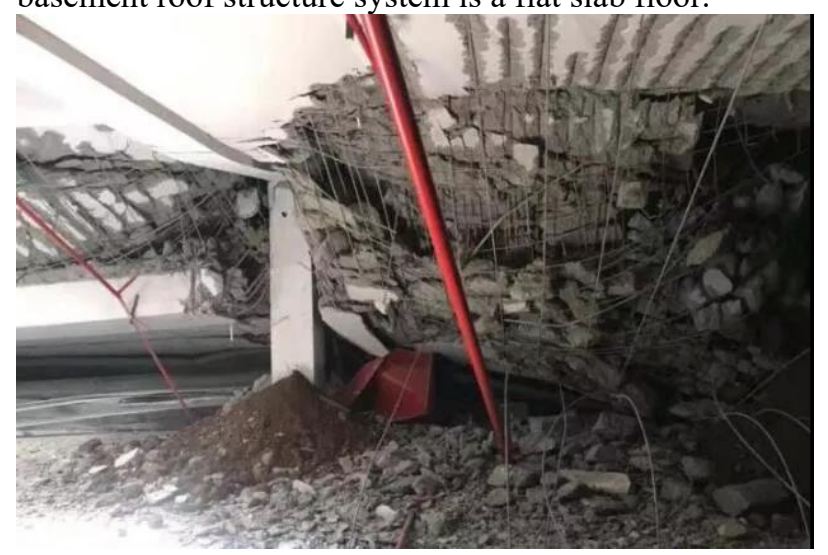

Fig. 1. The scene of the accident

\section{Characteristics of the flat slab floor system}

Due to limited land, the ground buildings are nearly saturated, it is difficult to build or expand parking lots on the ground. Many cities now choose to develop underground land and build underground garages. This method does not occupy the ground land, and can build squares and gardens on the roof surface of the garage, which improves the land utilization rate. The underground garage usually uses a flat slab floor structure to make the roof of the garage. A flat slab floor is a structural system that is placed directly on a column or wall. This structural system is also known as a slab column structure. It transfers the floor load directly from the slab to the vertical load-bearing structure and then to the foundation through the vertical load-bearing structure [1].

The flat slab floor used in the underground garage mainly has the following two structural forms. The first type is a flat slab floor with a column cap, as shown in Figure 2, consists of column, column cap, pallet and floor. The column caps and pallets are used to enhance the connection between the flats and columns, and also to ease the column-to-floor punching and reduce the calculation span. However, due to the column cap, the formwork support during the construction process is more complicated, and not aesthetically pleasing.

The second type is a flat slab floor without column cap, as shown in Figure 3, its composition consists only of columns and floors. This kind of floor slab is more beautiful, and the space utilization is more convenient,

\footnotetext{
* Corresponding author: 36957703@qq.com
} 
but the slab is more punched at the joint, and it is necessary to strengthen the reinforcement [1].

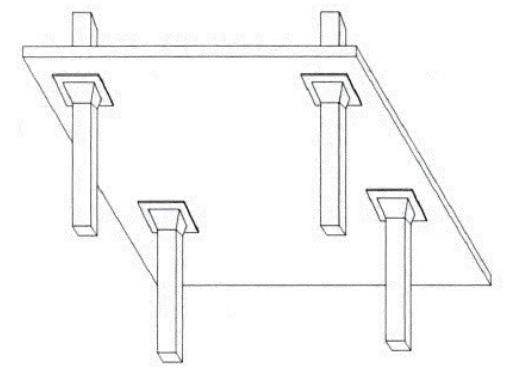

Fig. 2. Flat slab floor with column cap

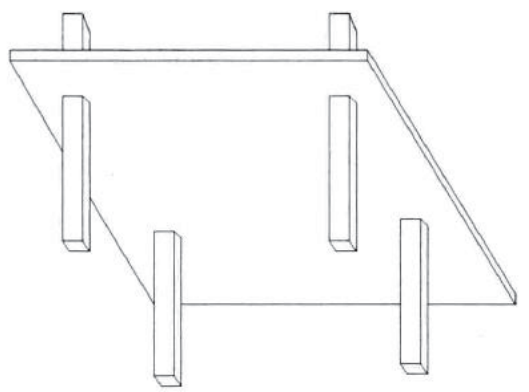

Fig. 3. Flat slab floor without column cap

Compared with the traditional beam-type floor slab, the flat slab structure has the following advantages: (1) the bottom of the board is flat, easy to install the ceiling and decoration of the house; (2) the layer height can be reduced; (3) the construction is convenient, and the construction period can be shortened; (4) the load transmission path is relatively simple and direct. Therefore, under certain conditions (such as single-layer basement), its comprehensive economy has great advantages over traditional beam-slab structures. However, the anti-collapse redundancy of the flat slab floor structure is not as large as the ordinary beam-slab structure, and the ductility is slightly worse. The damage is often sudden and there is no warning period.

\section{Reasons for the accident of the flat slab floor in the underground garage}

After analysis, in the underground garage roof collapse accident, the owners, construction units, designers have errors, should bear different responsibilities.

\subsection{The owner's request for the construction period is too fast}

The owner has too much consideration for cost control, and blindly requesting a shorter construction period is the cause of accidents. The construction party needs financing in the construction project and bears the heavy economic burden. Therefore, the owner hopes that the construction speed will be as fast as possible. In the design phase, the designer's design time is short, making the design rushed and there is no proofreading time. During the construction period, the construction party management is out of control, in order to complete as soon as possible. The basement roof is over-loaded, the transported giant truck was used to transport the soil, there is no temporary support, and the formwork is removed in advance, and any one of them would cause an accident.

\subsection{Construction management confusion}

Preliminary investigations revealed that when the accident occurred, the soil on the roof of the basement were too much, far exceeding the design load. This situation has occurred many times in previous similar accidents. For example, in November 2017, the second phase of a project in Hebei Cangzhou (which has been in normal use for three and a half years) partially collapsed. The main cause of the accident was that when the construction was carried out, the soil on the roof of the garage was 5 meters, far exceeding the thickness of the original design covering soil of 0.9 meters. In December 2016, a partial collapse accident occurred in the roof of the underground garage of a community in Heyuan. The main cause of the accident was too much soil accumulation. There were also heavy-duty vehicles on the roof of the underground garage, which seriously exceeded the design load.

\subsection{The design of the designer is flawed}

\subsubsection{Defective design method}

It can be seen from the numerous collapse accidents that the failure of the flat slab floor is the punching and shearing failure of the slab-column joints. The impact caused by the punching shear failure causes a continuous collapse of the structure. The current structural design method is based on the empirical coefficient method and the finite element method. The empirical coefficient method does not consider the unbalanced bending moment caused by the unequal span, unfavorable load arrangement and non-uniform load. The checking calculation of the punching force and shear force of the joint are not safe. The finite element method can consider the impact of the above factors, but does not consider the impact of the construction conditions on the punching force.

\subsubsection{Insufficient consideration of punching capacity of flat slab floor}

In this accident, the investigation results showed that there is no concealed beam on the basement roof. This leads to a decrease in the roof's ability to resist impact cutting. The accidents caused by the design mistake are more than this one. For example, in August 2017, an under-ground garage project in Shijingshan District, Beijing, used a bulldozer to backfill the soil on the roof of the basement, and the roof of the northeast side of the basement collapsed partially. The main cause of the accident is that the punching bearing capacity at the slab- 
column joint of the roof does not meet the requirements of the design specifications.

\section{Optimization improvement measures}

\subsection{The owner should pay attention to quality and not only focus on cost}

Construction requires a reasonable construction cycle. The construction party shall not excessively pursue the extremely fast construction speed, forcing designers and construction workers to compress the normal work cycle.

In order to improve the safety of the beamless floor, some locations need to be strengthened. Some companies engaged in drawing optimization work follow the owner's requirements and select design standards according to minimum standards. This behaviour makes the design security reserve insufficient. If the construction personnel are slightly careless during construction, it is prone to accidents. Owners must understand that rational optimization does not mean "cheapest optimization".

\subsection{The construction party should strengthen management}

Controlling construction load is an important method to avoid accidents. The following measures can be taken during construction:(1) Technical manager carefully read the requirements of the design drawings for the load, and avoid local overloading when designing the construction plan;(2) The driver of the transport vehicle strictly observes the traffic flow lines in the drawing. The transport vehicle cannot be parked at will;(3) When the roof is backfilled with soil, the driver should pay attention to the direction of backfilling to avoid the truck driving in the area already covered with soil;(4) During the construction, the local area where the actual load far exceeds the design load should be provided with a temporary support under the floor;(5) When the concrete strength does not reach the design value during construction, the formwork cannot be removed in advance.

\subsection{Designers improve the structure's ability to resist punching}

According to the structure failure mechanism, punching failure is brittle failure. To avoid such damage, we have no choice but to increase the safety margin of the carrying capacity. The designer must check not only the punching damage of the column to the column cap, but also the punching of the column cap to the floor. Both are equally important and cannot be left out. As shown in Figure 4, two cases need to be considered when checking the punching resistance of the flat slab floor of the column tray. The first case is to check the $45^{\circ}$ punching plane at the edge of the pallet, and the second case is to check the $45^{\circ}$ punching plane at the edge of the column. Both are indispensable[3]. If the height of the column cap is limited, it is a good idea to arrange stirrups in the column cap.

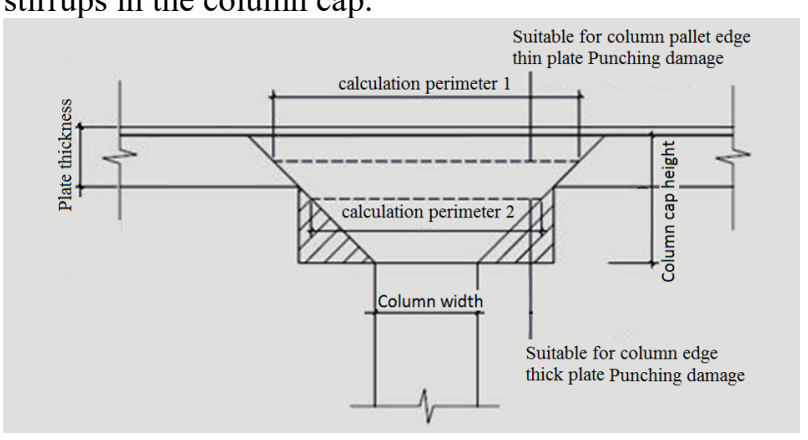

Fig.4. Punching check calculation section

\subsection{Setting concealed beam}

The slab without column cap shall be provided with a structural concealed beam in the strip on the column. The width of the concealed beam does not exceed the width of the column plus 1.5 times the plate thickness on both sides of the column. The area of the reinforcement in the upper part of the hidden beam should not be less than half of the area of the reinforcement in the strip on the column. The steel reinforcement in the lower part of the hidden beam is not less than half of the steel reinforcement in the upper part of the hidden beam. The stirrup diameter is not less than $8 \mathrm{~mm}$, the spacing is not more than $3 / 4$ times the thickness of the plate, and it should be arranged densely at both ends of the concealed beam [4]. The slab-column joints shall be equipped with shear studs or punching reinforcement according to the requirements of punching bearing capacity.

Concealed beams can improve the punching capacity and strengthen the structural integrity. To a certain extent, concealed beams can also transform brittle shear failure into ductile bending failure. Weak continuous collapse resistance is a natural defect of flat slab floor systems. To solve this problem, setting up a concealed beam is almost the only improvement method.

\subsection{Adopt finite element method design, and fully consider the construction conditions in the design}

The existence of unbalanced bending moment will reduce the redundancy of punching bearing capacity of floor. In normal design, we generally consider the load to be evenly distributed. We have not fully considered uneven loads such as local soil filling, automobile transportation, etc. In this case, the design would actually be insecure. At the design stage, we should calculate the bending moment when the load is unevenly distributed [5].

We assume that there is an underground garage with flat slab floor structure and the span is $8.1 \times 8.1 \mathrm{~m}$. We take this virtual garage as a research object and use the finite element calculation software to study the punching shear strength of slab-column joints under construction conditions such as unequal span, parking of fire trucks 
on the garage roof, and transporting and backfilling of large trucks.

We arbitrarily choose two adjacent spans with a total length of $8.1 \mathrm{~m} \times 2$. Then we modify the left span to $8.5 \mathrm{~m}$ and the right span to $7.7 \mathrm{~m}$. The total length of the two spans is unchanged and the span ratio is 1.1. We use the finite element calculation software to calculate the punching and shearing forces of the slab-column joints. When the span ratio is $1.1 \backslash 1.3 \backslash 1.5$ and the thickness of the covering soil is $1.0 \mathrm{~m} \backslash 1.2 \mathrm{~m} \backslash 1.5 \mathrm{~m}$. We use the empirical coefficient method to calculate the punching force when the spans are equal, and use this as the base number. We use the calculation results of the finite element method just now to compare with it to get the percentage increase of punching and shear strength of slab-column joints. The calculation result of the edge span is larger than that of the inner span, so we choose it to fill in Table 1.

Table 1. Percentage increase in punching and shear forces of slab-column joints when the side spans are not equal (\%)

\begin{tabular}{|c|c|c|c|c|c|c|}
\hline \multirow{2}{*}{$\begin{array}{l}\text { Span } \\
\text { ratio }\end{array}$} & \multicolumn{2}{|c|}{$\begin{array}{c}\text { Soil thickness } \\
1.0 \mathrm{~m}\end{array}$} & \multicolumn{2}{|c|}{$\begin{array}{c}\text { Soil thickness } \\
1.2 \mathrm{~m} \\
\end{array}$} & \multicolumn{2}{|c|}{$\begin{array}{c}\text { Soil thickness } \\
1.5 \mathrm{~m} \\
\end{array}$} \\
\hline & $\begin{array}{l}\text { Cap } \\
\text { Root }\end{array}$ & $\begin{array}{l}\text { Cap } \\
\text { top }\end{array}$ & $\begin{array}{l}\text { Cap } \\
\text { Root }\end{array}$ & $\begin{array}{l}\text { Cap } \\
\text { top }\end{array}$ & $\begin{array}{l}\text { Cap } \\
\text { Root }\end{array}$ & $\begin{array}{l}\text { Cap } \\
\text { top }\end{array}$ \\
\hline 1.1 & 59.6 & 12.7 & 12.2 & 13.9 & 13.9 & 16.0 \\
\hline 1.3 & 13.4 & 14.6 & 14.1 & 15.8 & 16.0 & 18.1 \\
\hline 1.5 & 15.4 & 16.7 & 16.2 & 18.0 & 18.4 & 20.7 \\
\hline
\end{tabular}

It can be seen from Table 1 that as the span ratio increases the percentage increase in punching and shear forces of slab-column joints increases, and at the same time increases with the increase of soil cover.

When backfilling the top slab, we calculated the load based on 2 earthmoving vehicles (one full and one empty) during construction. The mass of the earthmoving vehicle is $19 \mathrm{t}$ under no load and 50t under full load. The equivalent load can be taken as $22 \mathrm{kN} / \mathrm{m}^{2}$ on an $8.1 \mathrm{~m} \times$ $8.1 \mathrm{~m}$ two-way plate. We set the dynamic amplification factor to 1.3 , and when the roof is backfilled with soil, the equivalent load of the earthmoving vehicle is $28.6 \mathrm{kN}$ $/ \mathrm{m}^{2}$ [6]. We calculate the punching and shearing force of the central slab-column joint when the roof is covered with soil at $1.0 \mathrm{~m} \backslash 1.2 \mathrm{~m} \backslash 1.5 \mathrm{~m}$, and use this as the base. Then we calculate the punching and shearing force when the car is running, and compare it with the base to get the percentage increase, as shown in Table 2.

It can be seen from Table 2 that the load of earthmoving vehicles has a significant effect on the increase of punching and shearing forces of slab-column joints in thin-covered soil conditions, with an increase of $20 \%$ to $35 \%$, and has a small effect in thick-covered soil conditions, with increase only $5 \%$.

Table 2. Percentage increase in punching and shear forces of slab-column joints during construction of earthmoving vehicles (\%)

\begin{tabular}{|c|c|c|c|c|c|c|}
\hline & \multicolumn{2}{|c|}{$\begin{array}{c}\text { Soil thickness } \\
1.0 \mathrm{~m}\end{array}$} & \multicolumn{2}{c|}{$\begin{array}{c}\text { Soil thickness } \\
1.2 \mathrm{~m}\end{array}$} & \multicolumn{2}{c|}{$\begin{array}{c}\text { Soil thickness } \\
1.5 \mathrm{~m}\end{array}$} \\
\hline $\begin{array}{c}\text { With } \\
\text { earth } \\
\text { moving } \\
\text { vehicles }\end{array}$ & $\begin{array}{c}\text { Cap } \\
\text { Root }\end{array}$ & $\begin{array}{c}\text { Cap } \\
\text { top }\end{array}$ & $\begin{array}{c}\text { Cap } \\
\text { Root }\end{array}$ & $\begin{array}{c}\text { Cap } \\
\text { top }\end{array}$ & $\begin{array}{c}\text { Cap } \\
\text { Root }\end{array}$ & $\begin{array}{c}\text { Cap } \\
\text { top }\end{array}$ \\
\cline { 2 - 7 } & 34 & 34.4 & 20.2 & 20.8 & 4.8 & 5.6 \\
\hline
\end{tabular}

\section{Conclusions}

The flat slab floor is a very economical structural form used in the underground garage roof. The safe construction and use of beamless slabs require the cooperation of owners, constructors, and designers. Especially for designers, they have heavy responsibilities and must do the following in the design.

(1) The design method should choose finite element method which is more secure and reasonable; if the empirical coefficient method is used, the calculation result should be increased by $5 \%$;

(2) Designers must pay attention to checking the antipunching capacity in design;

(3) Designers design concealed beams according to structural requirements to increase the ability of the structure to resist continuous collapse;

(4) Designers fully consider the construction load of large construction vehicles when designing;

(5) The total design load must be clearly stated on the drawing;

(6) For the location with large local overload, the designer should put forward suggestions for temporary support.

\section{Acknowledgement}

This research was financially supported by Hubei education department humanities and social sciences research project under Grant No. 19Y078: The establishment and research of the influencing factors and combination prediction model about carbon emission under economic new normal situation in Hubei province.

\section{References}

1. J.Han, Experimental Study and Finite Element Analysis Hollow Girderless Floors under Vertical Load. Zhejiang University, (2015)

2. B.Y. Zhao, Research and Analysis of Bearing Capacity of Flat Slab Floor. Tianjin Institute of Urban Construction, (2012)

3. L.Z.Liu, Common Problems and Improvement Measures in Design of Beamless Floor Structural system. Residence, 15:171-172(2018)

4. R.Zhang, Common Problems and Improvement Measures in Design of Beamless Floor Structural system.Housing and Real Estate, 34 :85 (2018)

5. J.R.Chen,H.Q.Xiong,S.M.Peng. Design Moment Analysis of Cast-in-situ reinforced Concrete Hollow Beamless Floor. Journal of Wuhan University of Technology,16 (7):24-26(2002)

6. Y.J.Xiao,J.G.Han, Research on the Equivalent Load of Earthmoving Truck on Pit Trestle Deck. Structural Engineer,33(5):179-180(2017) 